\title{
On the Exploration and Practice of Core Capabilities of Excellence Electronics Engineers
}

\author{
Yueqian $\mathrm{Fu}$ \\ The school of electronic and Information engineering \\ Ningbo University of technology \\ Ningbo, China \\ Fyqfyq777@163.com
}

\begin{abstract}
Based on the exploration of the structure of the core capabilities of excellence electronics engineers, this paper proposes to establish the cultivating approaches which can improve and enhance tangibly the students' inventiveness, applying and teamwork abilities meeting the demands of the regional electronics industries for the modern electronics engineering persons with ability through the creation of TRIZ innovative curriculum, the introduction of the research-type study, the implementation of the practice teaching model driven by projects and the promotion of the Second Classroom of "Technology Innovation".
\end{abstract}

\section{Keywords-innovation; application; collaboration; engineer}

\section{INTRODUCTION}

The engineering education reform has absorbed the worldwide attention in the unprecedented ranges and deepness which is due to the engineering education shoulders the heavy tasks of the training of hundreds of millions of engineering talents who are just those men who had created, are creating and will continue to create the engineering, technology and even all material civilization in the world, promoting economic and industrial development, leaving the impacts on people's thinking and lifestyle. In the past 200 years, the engineering education had been created a huge brilliant achievements, nevertheless, in the 21 st century, the global industry and economic development make the engineering education face severe challenges of the shortage of a large number of high-quality engineering talents.

The engineering education in our country conditioned by the traditional concept and funding, just carrying out basic science education. Since the increased enrollments ,the practice content of engineering education tends to be more" verification, mechanism and unionization", lacking of the cultivation of "Designing , autonomy , innovation", as its result, a vicious cycle has appeared that enterprises extremely need a large number of application-based and innovative persons with ability, meanwhile, the employment rate declines lower and lower. What the most lacking in the today's engineering students' ability constructure is the innovation capability. In essence the engineering disciplines is needed to be practiced, therefore, the cultivation of the innovation capability must be reached by the practice process of solving problems. The higher engineering education in U.S had caused the teachers in the engineering education world and their

\author{
Jianming Lou \\ The school of electronic and Information engineering \\ Ningbo University of technology \\ Ningbo, China \\ 1jm@nbut.cn
}

cultivated students with too little experience to meet difficultly the demands of the industrial world because of too much emphasis in teaching the engineering science knowledge and despising the engineering practice. [1] Now, the American scholars began a new meaning and definition of the engineering education. It is generally considered that "the project itself is the development and application of scientific knowledge as well as on technology, which is a creative professional to meet the social needs." Based on the clarifying of the engineering practice nature and innovative feature, they proposed that the reform philosophy of "returning to engineering practice ", emphasizing on the teaching that "the practice is the fundamental engineering" and the training in engineering practice of teachers and students, especially the training of projects design application ability of students [2]

Currently, the industrial circle considers that the main problems exiting in the domestic higher engineering education are: the engineering graduates generally lack the workflow and cultural understanding of the modern enterprises with a slow induction adaptation, the lack of experience of teamwork, less communication skills, poor manipulative ability, innovative spirit and ability, initiative work, and weak professional ethics, and professionalism, etc. [3]. This condition has effected directly the sustainability of our higher engineering education, which is not adapted to the trends of complication of the current engineering practice as well as the developing direction of the "Large Engineering Education" fashioned in the fields of the world higher engineering education.

In 2010, "Excellent Engineer Training Program" was adopted by the National long-term Education Reform and Development Plan Scheme. With its implementation, it indicated that China had started a large-scale engineering education reform aiming at training a large number of all kinds of engineering and technical personnels of high quality with the strong innovation capacity who adapt to the economic and social development needs, serving the national new road of industrialization, the establishment of an innovative country and implementing of the strategy of building up the strength of the country with talented people.

\section{THE REQUIREMENT OF THE ENGINEERING TALENT CAPACITY FROM THE INDUSTRIAL CIRCLE}

According to related researches, engineers in the 21st century should have the abilities as follows: 
Knowing everything--who can find out rapidly the information related to the assignments, knowing how to determine and dealing with these information and turn these information into knowledge.

Omnipotent-- who can master the basic elements of the engineering profession, judging rapidly what to do, obtaining rapidly the tools needed and be familiar with these tools.

Having the ability of cooperating with anyone in anywhere--who should have the ability with better communication skills and teamwork, understanding the whole picture and the facing issues and cooperating with others effectively.

Having the imagination power, able to turn dreams into reality--who should have the entrepreneurship, imagination power and management skills, identifying the demands, proposing the new solutions and could have been responsible in the end.

Among the capabilities mentioned above, the "knowing everything" can be reached basically as long as mastering the application of internet search tools and some certain logical induction ability. The other three points can be summarized as "Knowledge Application ", "Collaboration Capability." and "Innovation Ability".

\section{A. "Originality Innovation" is the major theme of the engineering.}

In recent 20 years, China's sustained rapid economic development has created a miracle in the history of human economy, during which a large number of persons with ability have been trained, thereby strengthening the national power greatly, laying a solid foundation for the future sustained development. Nevertheless, this kind of development is still a growth process of low value-added and low-profit, which is mainly reflected in that labor-intensive industries with the processing industries as the main part are developed at the expense of lots of cheap labors and other resource. Although this is necessary for a big country like China with a very low starting point in the stage of the primitive accumulation, this kind of economic development mode would not be sustainable and could not be allowed to continue.

According to statistics, only 3 of ten thousands of Chinese enterprises have their own proprietary intellectual property rights, meanwhile most of Chinese enterprises just manufacture the products invented and designed by the foreigners, i.e OEM. This is the primary cause why the profit margin of China manufacturing industry is at a very low position in the whole industry chain. Multinational companies rely on profits by creating, and Chinese companies rely on profits by manufacturing. There is a typical portrayal that IPHONE has made Apple Inc. rather than Foxconn.

As the technology gradually becomes a common commodity, engineers will not be confined only to complete the technical work. In the 21 st century, each engineer must be outstanding, they can not rely on repeated conventional techniques for a purpose of enjoying a high standard life, but everyone shoulders the responsibility of proposing new originalities and implement solutions. Both for the country and individuals, the innovation would be the key factor for the future development. The engineering education must make the engineers have ability of the innovation and integration of resources to achieve the innovation.

It will need a large number of engineering talents with innovative ability to change "Made in China" to "Created in China", to "Building an Innovation -oriented Country".

\section{B. “Application” represents the engineer's professional competence}

The engineering education aims at making students have the ability to be equal to the future job, becoming a qualified citizen and a qualified industrial personnel. Therefore the professional education should be based on job-wanted to cultivate students making study to serve the practical purpose, linking theory with practice to adapt the ability and quality needed in the future job-wanted, that is the commonness of all the majors in stead of the speciality of the "Vocational Education". According to different training levels, the engineers can be subdivided into the Application-based. Designing, Research and Development, respectively corresponding to undergraduate course, master and doctoral degree education, however, there are no absolute limits between them, they should have the basic knowledge of the profession, basic skills and integrated application capabilities.

\section{C. "Cooperation" represents the non-technical vocational skills of engineers}

Engineers will not only often provide their services for the different countries' manufactures and products in sales, but also the more and more designing and development of the products are completed by teams consisted of different frameworks and different persons with different cultural backgrounds. The desired ability of the teamwork and communication skill is the basic requirement of the modern flat world for the engineers as well as the necessary requirement of social division of work.

\section{WAYS OF CULTIVATION}

The innovation capacity, the application ability and the collaboration capability are the core capabilities which the modern engineers must possess, whose cultivating process is not independent of each other but combined with each other, keeping a close connection and improving simultaneously. Figure 1 below, Ability Cultivation Diagram shows the "innovation, application and collaboration" of engineers.

\section{A. Introduction in "TRIZ Course" to cultivate the innovative thinking}

The innovation ability refers to the new threads and methods of human to discover new problems and solve them through innovative thinking activity based on the wealth of knowledge and spacious view and the capacity of creating new products, new technology and new methods through innovation practice, which is a basic feature of an outstanding engineering and technical personnel as well as an important mark why an excellent engineer will be "excellent". Engineers 
at the undergraduate level should be able to implement innovatively the products' production, marketing and service on the project site or projects' construction, operation and maintenance in order to become an excellent application-based innovative engineer.

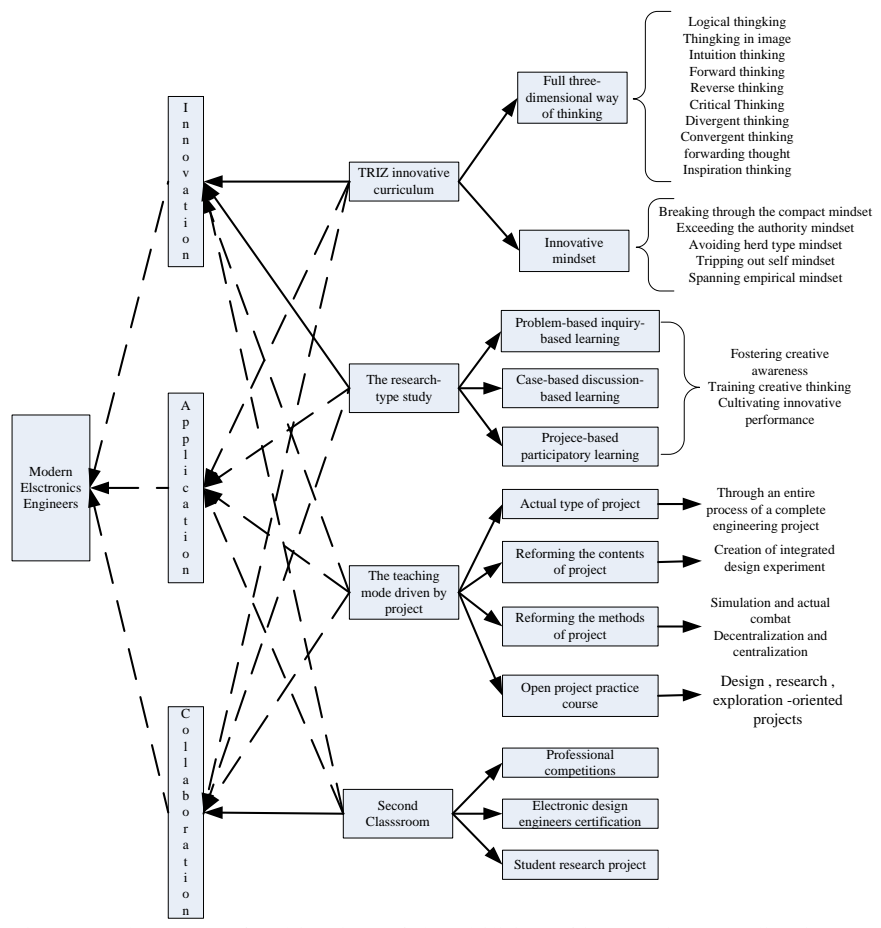

Figure 1 the ways of cultivation of the abilities of innovation, application and collaboration of engineers

So far, the innovation is linked with the inspiration, lots of research stress the importance of innovation for engineering talents, but do not come up with effective measures of special training, only as a byproduct of a theoretical study, a project practice and community activities, now we lead in the TRIZ(The Theory of Inventive Problem Solving) innovative course to train students with the innovative thinking to the point in order to lay foundation for the cultivation of the innovative ability.

Though the innovation ability is a "Soft Capacity" with a personalized development space, which will present a complete different development according to everyone's different environment, interest and ability, nevertheless, it still has a certain regularity. TRIZ theory lies in providing a systematic theory, methods and tools for the people to discover problems and solve them creatively, which discovers that there are rules to follow in the product improvement, the technological change and innovation in any field. Based on mastering these rules, people can conduct dynamically the product innovation and predict the future trends in products. The modern TRIZ theory system is mainly consisted of innovative thinking methods and the problem analyzing methods; technology system laws of evolution; technical contradiction solving principles; innovation standard solution; inventive problem resolution algorithm (ARIZ); knowledge base built on the base of the Engineering Principles such as Physics, chemistry, geometry[5],etc.
The modern students are those of imagination and curious about new things, with the riches of knowledge and the accumulation of experience, their thinking will be more agile and easier to burst out of the spark of new inspiration. However, because of the influence of the traditional examination-oriented education system, their thinking is often the planar logical thinking and convergent thinking. The leading in the innovative course such TRIZ, trial \& error method and brainstorming method as the systemic training of their innovation thinking ability, guiding them into the full three-dimensional way of thinking such logical thinking, image thinking, intuitive thinking, positive thinking, reverse thinking, critical thinking, focused thinking, divergent thinking, forwarding thinking, thinking of inspiration as makes them break through the book-based mindset, exceed the authoritative mindset, avoid the conformity mindset, trip out of the self-type mindset, span the empirical mindset to establish innovative mindset.

\section{B. Carrying out the research-type study adapting to the cultivation of innovation ability}

The research-type study is a learning methodology, a generic term of a type of learning methods and the main form of inquiry-based learning based on problems, discuss learning based on cases and participatory learning based on projects, which will benefit the formation of students' innovative consciousness, the cultivation of students' creative thinking, the development of innovative practice in future and the nurturance of students' innovative quality, it has been generally respected by the world -renowned universities in many countries, which is not only a teaching organizational form and teaching method suitable for the excellence engineer training but also plays an irreplaceable role in the cultivation of the excellent engineers innovative ability. It is the sticking point of the innovative ability training to carry out the research-type study on the professional curriculum including major basic courses and project practice, in which its selected topics should be development-oriented issues with enough challenging in the result of encouraging students to think things out for themselves, breaking through the mindset, seeking originality and exceptionality, organizing well classroom discussions, encouraging students to speak out freely, allowing for differences of opinion, cultivating students' flavors, encouraging individual talents, laying emphasis on personality development, focusing on the learning process rather than learning outcomes.

For instance, as to the "Major Introduction" course, we can require students divided into groups to complete" the Cuttingedge Engineering Technology Research of Electronics Sciences", "the Cellphone Development History and Prospects", "Electronics Engineers in Your Imagination" and so on. We can also start some "Non-Professional Open Project" such as "the Status and Optimization of Traffic Flow on campus", etc. In major courses, students can be required to complete research, write reports, conduct grouping reports in the purpose of cultivating their innovative ability, exercising their teamwork and enhancing their application capacity. 


\section{Establishing the practice model taking "Project Drive" as its main line}

A personal experience of the entire process of research, design and implementation of an entire project will play an important part in the cultivation of the major ability of application-type electronics engineers. The study in enterprises will provide students with a practice opportunity, making them familiar with the electronics production mode, on site operation regulations and technical ability, however, there are no major practice opportunities for a large number of students there due to the technical security and number of students. Then the exploitation of a batch of typical projects suitable for teaching with the features of system, cutting-edge, type, application and interesting in the practice environment of keeping maintenance of emulation with the engineering design and engineering implementation by using the instruments and equipments in accordance with the engineering design enabling students to have a emulation opportunity to participate in a full process of integrity of an engineering project in order to strengthen their ability of engineering, design and innovation and remedying the defects of the major ability training studying in enterprises will be very significant in the aspect of the engineering ability cultivation.

We have developed the engineering projects suitable for teaching such "Wireless Geophone System Design "," Infrared Voice Transmission System Design ", "Multi-User Access Control System Design Based on Fingerprint Identification Technology", "Remote Temperature Buzzer Design Based on GSM Network", " Camera-based Intelligent Tracking Car", "Ethernet-based Intelligent Electricity Monitoring System Design ","FPGA-based Twin-Channel DDS Signal Generator Design" as the practices for students' grouping implementation during which 4-5 persons in a group determine the project topic with each group's different topic. Each instructor will be responsible for four groups, organizing students to discuss and checking the progress every week; Within project teams, we encourage students to collaborate with each other, discuss at fixed period, consult literatures, propose schemes, write the software emulation, get out the gaps, conduct continuous improvement, complete the "attending to trifles and neglecting the essentials"; In the collecting phase, the students will finish production and adjustment of physical works and PPT exchange reporting; Each group will introduce by PPT their objectives, programs, simulation, matters, ingathers and so on. Teachers give marks based on exchanges and in-kind.

During studying the open project design practical optional academic course, taking a group as a unit, students can propose the topics of the engineering projects of design-type, research-type, exploration-type, which will be approved and initiated by teachers, in the following, a student team will complete autonomy the information retrieval, program selection, design and making, test and summarizing, in the final stage, each team will conduct PPT exchange reporting.

This paper propose to push positively the Electronic Design Engineer Certification and Undergraduate Electronic Design Contest. In the sophomore stage the electronic design interest group should be established to cultivate strongly students' electronic process capability and stimulate their interest in learning. In the junior stage we should establish the training group of the electronic contest to select students of different strengths, dividing them into groups to compose teams, participating in National, Provincial Undergraduate Electronic Design Contest, encouraging students to apply for the Provincial Undergraduate Scientific and Technological Innovation Projects, organizing students to pass the Electronic Design Engineer Certification.

\section{CONCLUSION}

The training strategy completed by establishing a series of TRIZ innovative courses, introducing in the research-type study, implementing the teaching mode of project drive, extending the second classroom of the "Technology Innovation" will not only stimulate students' innovative capacity, enhancing their engineering application ability and increasing their collaboration experience with a team project in the result to improve effectively the efficiency of the training of core competencies of the modern electronic engineers, but also touch students' heart to make them generate the passion for innovation. The students exercised through the project practice will own an alive ability rather than a dead knowledge.

\section{REFERENCES}

[1] Li Zheng, Li Juqi, "The development trend analysis of international higher engineering education reform ". Higher Education Exploration , 2005, ( 2 ) ,pp. 30-32..

[2] Zhu Hong , Li YuZhu . On the Development Trend of Curriculum Reform of Higher Engineering Education in our country [J]. , Anhui University of Technology ( Social Science Edition ), 2006, ( 2 ) ,pp. $72-$ 74.

[3] Zhang Huiping Dai Bo, Liu Na , etc. On the automation curriculum reform and practice based on the education concept CDIO [J]. Electrical \& Electronic Education ", 2009, (Z2), pp. 138-141.

[4] Gretar Tryggvason, Diran Apelian, Cha Jianzhong, Feng Lei . On the engineering education Reconstruction In 21 century [J]. " China University Teaching ", 2008, ( 12 ),pp. 84-86.

[5] Lu Qiang, On the function-oriented visualization innovative conceptual design method [D], Hefei University.2010. 